\title{
Psychophysical Measurements of Luminance Contrast Sensitivity and Color Discrimination with Transparent and Blue-Light Filter Intraocular Lenses
}

\author{
Marcelo Fernandes da Costa - Augusto Paranhos Júnior - Claudio Luiz Lottenberg • \\ Leonardo Cunha Castro · Dora Fix Ventura
}

Received: May 29, 2017 / Published online: August 9, 2017

(C) The Author(s) 2017. This article is an open access publication

\begin{abstract}
Introduction: The purpose of this study was to measure luminance contrast sensitivity and color vision thresholdfs in normal subjects using a blue light filter lens and transparent intraocular lens material.

Methods: Monocular luminance grating contrast sensitivity was measured with Psycho for Windows (version 2.36; Cambridge Research Systems) at 3.0, 6.0, 12.0, 20.0, and 30.0 cycles per degree of visual angle (cpd) in 15 normal
\end{abstract}

Enhanced content To view enhanced content for this article go to http://www.medengine.com/Redeem/ D4E8F0600E81B8D7.

M. F. da Costa $(\bowtie)$. D. F. Ventura

Departamento de Psicologia Experimental, Instituto de Psicologia, Universidade de São Paulo, São Paulo, Brazil

e-mail: costamf@usp.br

M. F. da Costa - D. F. Ventura

Núcleo de Neurociências e Comportamento e

Neurociências Aplicada, Universidade de São Paulo, São Paulo, Brazil

A. P. Júnior · L. C. Castro

Departamento de Oftalmologia, Universidade

Federal de São Paulo, São Paulo, Brazil

A. P. Júnior · C. L. Lottenberg

Hospital Israelita Albert Einstein, São Paulo, Brazil subjects (eight female), with a mean age of 21.6 years $(\mathrm{SD}=3.8$ years). Chromatic discrimination was assessed with the Cambridge colour test (CCT) along the protan, deutan, and tritan color confusion axes. Both tests were performed in a darkened room under two situations: with a transparent lens and with blue light filter lens. Subjective impressions were taken by subjects regarding their visual experience under both conditions.

Results: No difference was found between the luminance contrast sensitivity measured with transparent and blue light filter. However, $13 / 15(87 \%)$ of the subjects reported more comfortable vision with the blue filter. In the color vision test, tritan thresholds were significantly higher for the blue filter compared with the transparent filter $(p=0.003)$. For protan and deutan thresholds no differences were found.

Conclusion: Blue-yellow color vision is impaired with the blue light filter, and no impairment occurs with the transparent filter. No significant differences in thresholds were found in the luminance contrast sensitivity comparing the blue light and transparent filters. The impact of short wavelength light filtering on intrinsically photosensitive retinal ganglion cells is also discussed.

Keywords: Blue filter IOL; Chromatic filtering; Chromaticity discrimination; Color vision impairment; Luminance contrast sensitivity 


\section{INTRODUCTION}

An intraocular lens with a blue light filter was designed to absorb ultraviolet radiation. In addition, the yellowing of these lenses also absorbs short wavelength radiation. Studies have been conducted to measure the effect of blue-light-filtering intraocular lenses (IOL), which contain a yellow chromophore on color contrast sensitivity compared with an identically designed intraocular lens without a blue-light filter. Many of these studies did not find a statistical difference in the color vision and contrast sensitivity measured with the blue filter lens when compared with the clear lens [1-9].

On the other hand, Mester [10] found that the color vision for hues in the blue region, assessed with the Farnsworth-Munsell 100-hue test, was significantly reduced under mesopic and photopic conditions for the blue-light-filtering IOL. However, the measurements of the total error scores were within normal values and no color vision alterations were reported by the patients. In another study, Pierre et al. [11] reported a reduction in the luminance contrast sensitivity in patients with blue filter IOL.

A patient who complained of color vision disturbance was evaluated in Shah et al. [12]. The patient had a clear AcrySof lens in one eye and yellow AcrySof lens in the following eye. That patient referred an intolerant color vision disturbance. Those authors suggest that different IOLs should be avoided.

All these previous studies used the Farnsworth-Munsell or Lanthony D-15 to assess color vision. An advantage of computerized color vision tests when compared with older color vision tests classically used, such as the Farnsworth-Munsell 100-Hue Test, has been largely reported in the literature. The advantage is supposed to be due to some aspects related to the program presentation of trials and to the advances in color reproduction of computerized systems. Some evidence supporting the advantage experienced came from the (1) rigorous psychophysical methodology is used, (2) changes in the chromatic steps can be dynamically adjusted according to the subject's responses,
(3) the chromatic steps has high resolution, which has been sufficiently fine to allow threshold measurement, and (4) online computation and index calculations are available. Limitations of the computerized tests are that most of them are new and produced for experimental applications, and most are not commercially available. Exceptions to that limitation are the Cambridge Colour Test (CCT; Cambridge Research Systems, Ltd., Rochester, UK), which was designed by Mollon and Reffin [13] and is available commercially. Since the CCT is a quantitative test and based on the adaptive psychophysical test, some studies have been provided evidence for higher sensitivity to detect subtle color defects [14-23] compared to other methodologies.

The CCT allows simultaneous testing of the parvocellular and koniocellular visual pathways, which are related to red-green and blue-yellow chromatic vision, respectively, by the measurement of thresholds in cone isolation for the protan, deutan, and tritan confusion lines $[16,21,24]$. The possibility of threshold measurements in these chromatic cones is based on the findings that the responses of dwarf and bistratified ganglion cells result from linear combinations of cones entries, which was proposed in different studies [25-27]. Additionally, intrinsically photosensitive retinal ganglion cells (ipRGC) whose spectral absorption peak is located in a short-wavelength region of light spectrum could be affected by the blue light filtering of colored lenses [28]. Impairment of the ipRGC functions has been related to circadian disorders, sleep malfunctions, photophobias, and possibly mood disorders presented in several patients.

Castro et al. [29] tested the blue light spectrum filter (BLSF), which is similar in light spectrum transmittance to the intraocular lens Acrysof Natural ${ }^{\mathrm{TM}}$, on two protocols of visual perimetry: the standard automated perimetry (SAP) and short-wavelength automated perimetry (SWAP). The authors had found a statistically significant reduction in mean deviation and foveal threshold values for SWAP with the use of the blue light spectrum filter lens, but normal values in SAP measurements. 
In this study, the same BLSF lenses tested on Castro et al. [29] work were used to measure the color vision discrimination threshold with the CCT, a controlled and sensitive psychophysical test, in normal participants to avoid the interferences produced by the surgery procedures presented in all the previous studies. Additionally, the luminance contrast sensitivity was also measured.

\section{METHODS}

\section{Subjects}

We evaluated the contrast sensitivity of 15 participants (eight female) ranging from 18 to
31 years old (mean $=21.6 ; \mathrm{SD}=3.8$ years), students of the University of São Paulo. Visual acuity was measured at $4 \mathrm{~m}$ using the ETDRS chart (tumbling E-Xenonio, Brasil). All subjects had normal eye fundus clinically evaluated, 20/20 best corrected visual acuity or better and no history of congenital or acquired color vision defect. Table 1 presents the demographic data. All procedures were approved and they were in accordance with the ethical standards of the ethical committee on human experimentation and with the Declaration of Helsinki 1964, as revised in 2013. Informed consent was obtained from all participants for being included in the study. The study was designed and conducted as an experimental study and no register was due to clinical trial procedures. All

Table 1 Contrast sensitivity data obtained with IOLt and IOLy

\begin{tabular}{|c|c|c|c|c|c|c|c|c|c|c|c|c|c|}
\hline \multirow[t]{2}{*}{ ID } & \multirow[t]{2}{*}{ Age } & \multirow[t]{2}{*}{ Gender } & \multirow[t]{2}{*}{ Eye } & \multicolumn{5}{|c|}{ Contrast Senitivity IOLt ${ }^{a}$} & \multicolumn{5}{|c|}{ Contrast Senitivity IOLy ${ }^{b}$} \\
\hline & & & & $\overline{3^{c}}$ & 6 & 12 & 20 & 30 & $\overline{3}$ & 6 & 12 & 20 & 30 \\
\hline 1 & 23 & M & OS & 202.0 & 129.0 & 76.8 & 14.6 & & 48.0 & 76.8 & 34.7 & 7.6 & \\
\hline 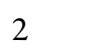 & 25 & $\mathrm{~F}$ & OD & 195.0 & 158.0 & 64.6 & 13.2 & & 188.0 & 129.0 & 64.7 & 14.2 & \\
\hline 3 & 18 & $\mathrm{~F}$ & OD & 182.0 & 120.0 & 85.3 & 24.6 & 29.9 & 232.0 & 182.0 & 101.0 & 47.3 & 10.7 \\
\hline 4 & 21 & $\mathrm{~F}$ & OS & 257.0 & 202.0 & 101.0 & 39.8 & 14.7 & 240.0 & 158.0 & 125.0 & 39.8 & 19.0 \\
\hline 5 & 21 & M & OS & 98.0 & 105.0 & 47.3 & 17.4 & 3.0 & 138.0 & 82.3 & 45.7 & 17.4 & 1.7 \\
\hline 6 & 23 & $\mathrm{M}$ & OD & 101.0 & 91.4 & 44.4 & 14.6 & 1.7 & 105.0 & 105.0 & 69.4 & 18.0 & 3.0 \\
\hline 7 & 19 & $\mathrm{~F}$ & OS & 112.0 & 71.7 & 42.7 & 10.4 & 2.2 & 158.0 & 138.0 & 74.1 & 31.3 & 3.0 \\
\hline 8 & 19 & $\mathrm{~F}$ & OD & 129.0 & 116.0 & 45.7 & 26.3 & 3.8 & 129.0 & 105.0 & 52.5 & 31.3 & 1.1 \\
\hline 9 & 28 & $\mathrm{M}$ & OS & 69.4 & 39.7 & 9.7 & 2.9 & 1.0 & 56.2 & 25.4 & 7.6 & 3.0 & 2.8 \\
\hline 10 & 31 & $\mathrm{M}$ & OS & 94.5 & 33.7 & 11.2 & 3.7 & 1.5 & 39.9 & 9.3 & 2.4 & 1.4 & 1.0 \\
\hline 11 & 18 & $\mathrm{~F}$ & OD & 125.0 & 101.0 & 52.5 & 20.1 & 15.4 & 113.0 & 69.8 & 56.2 & 26.3 & 8.2 \\
\hline 12 & 20 & $\mathrm{~F}$ & OD & 153.0 & 153.0 & 133.0 & 72.0 & 24.6 & 138.0 & 148.0 & 109.0 & 76.8 & 25.4 \\
\hline 13 & 21 & $\mathrm{M}$ & OS & 158.0 & 116.0 & 51.0 & 14.3 & 5.6 & 120.0 & 98.0 & 41.2 & 14.6 & 3.7 \\
\hline 14 & 18 & $\mathrm{~F}$ & OS & 138.0 & 129.0 & 71.7 & 20.0 & 3.6 & 188.0 & 158.0 & 94.5 & 37.2 & 2.5 \\
\hline 15 & 19 & $\mathrm{M}$ & OD & 50.7 & 37.2 & 19.6 & 5.1 & 6.6 & 77.2 & 42.8 & 26.3 & 10.0 & 3.4 \\
\hline Mean & 22 & & & 137.63 & 106.84 & 57.08 & 19.93 & 8.73 & 138.02 & 101.82 & 60.29 & 25.08 & 6.58 \\
\hline SD & 3.9 & & & 54.89 & 47.32 & 33.34 & 17.26 & 9.50 & 57.86 & 51.32 & 36.12 & 19.88 & 7.58 \\
\hline
\end{tabular}

a IOLt-transparent IOL

b IOLy-blue light filter IOL

c Value in cicles per degree of visual angle (cpd) 
participants were tested monocularly in a darkened room. The order of the tests and the eye tested were randomly selected.

Thirteen of the 15 subjects ranging in age from 18 to 31 years old $($ mean $=22.0$; $\mathrm{SD}=3.9$ years) performed the color vision test. After the first test, two participants did not show interest in collaborating with the second test and, in both cases, the second test was the color vision test.

\section{Equipment and Procedures}

\section{Filters}

The BLSF lens was manufactured using an organic resin lens (CR 39, Essilor do Brasil, Manaus, AM, Brazil) and received a yellow coloration lens tint (BPI Filter Vision 450-UV blocker-code BPI\#37870, Brain Power Inc., Miami, FL, USA). The spectral transmittance of the BLSF was measured by using a miniature fiber optical high-definition spectrometer (S2000, Ocean Optics Inc., Dunedin, FL, USA), and the light transmittance was equivalent to the spectral transmittance curve of the Acrysof Natural $^{\text {TM }}$ IOL (Fig. 1).

The blue and the transparent filter were used in front of the tested eyes attached in an ophthalmological lens support. The order of the lens attached was randomly selected.

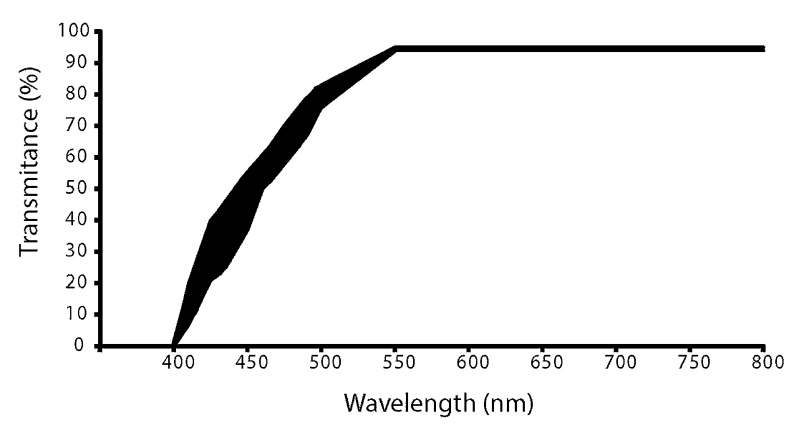

Fig. 1 AcrySof Natural ${ }^{\mathrm{TM}}$ spectral transmittance curve (6.0D-30D range). The thickening of the curve line between 400 and $500 \mathrm{~nm}$ is due to the different thicknesses of the IOLs secondary to the spherical power, causing differential blue light absorption. $P$ Protan, $D$ deutan, $T$ tritan Adapted from Castro et al. [29]

\section{Color Vision Test}

The evaluation of the chromaticity discrimination was performed using the Cambridge Colour Test (CCT v2.0-Cambridge Research Instruments, Rochester, UK), running on a PC (DELL Dymension XTC-600), coupled to the VSG 2/5 graphic board (Cambridge Research Instruments, Rochester, UK). The stimuli were generated in a color monitor of high-resolution (Sony FD Trinitron model GDM-F500T9; Sony Corporation, Tokyo, Japan). The chromaticity measurement was performed in a dark room with the participant positioned at $3 \mathrm{~m}$ from the monitor.

The stimulus provided by the Cambridge Colour Test is a spatial and luminance noise similar to those used in the Ishihara test (Kanehara \& CO., Ltd, Tokyo, Japan) or the American Optical Hard-Rand-Rattler test (Richmond Products, Boca Raton, FL, USA). The target was a letter $C$ (Landolt " $C$ ") that differed in chromaticity from the background chromaticity (coordinates 0.1977, 0.4689 $u^{\prime} v^{\prime}$ of the CIE 1976 color space) (Fig. 2). The Landolt $C$ gap had a size of $1.25^{\circ}$ of visual angle, with the outer diameter of $5.4^{\circ}$ and the inner diameter of $2.75^{\circ}$ at the test distance. Both target and background were composed by a spatial noise built of small patches of varying sizes $(0.5-2 \mathrm{~cm}$ in diameter) and presented six levels of luminance $(8,10,12$, 14,16 , and $18 \mathrm{~cd} \mathrm{~m}^{-2}$ ) randomly distributed in the display. This design using spatial and luminance noise aiming to avoid the influence of cues derived from luminance differences or from target contours (simultaneous contrast) in the intended chromaticity discrimination.

The target was randomly presented based on a 4-alternative forced choice rule with the "C" opening occurring in one of four positions: up, bottom, right, and left and appeared for $3 \mathrm{~s}$. The participant task was to indicate the position of the " $\mathrm{C}$ " opening using an appropriated four buttons response box (CT3-Cambridge Research Instruments, Rochester, UK). The participants had up to $15 \mathrm{~s}$ to give the response.

A single staircase psychophysical procedure was used for discriminations threshold measurement. For each color confusion axis the staircase began with a high saturated chromaticity, which changed along the vector 


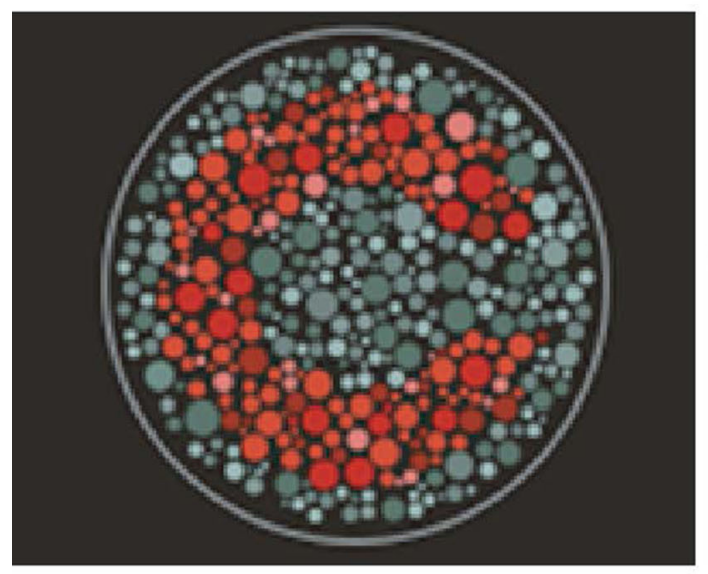

Fig. 2 Left image of the stimulus provided by the CCT, showing the spatial and luminance noise (small patches of different diameters and luminances) and the letter " $\mathrm{C}$ " formed by the same patches at a chromaticity that differs from the background. Right CIE chromaticity diagram (1976 u'v') used by the CCT. The gray area indicates all

connecting it to the background chromaticity. The chromaticity change depended on the participant's response on a one-up-one-down rule: the target chromaticity approached the background chromaticity at every correct response and moved away from the background chromaticity every time there was an incorrect response or no response was given during the $15 \mathrm{~s}$. The chromaticity excursion along the vectors ranged from 0.1100 to 0.0020 units of CIE $1976 u^{\prime} v^{\prime}$ considering a specific adaptive rule for calculating the next stimulation chromaticity. After six response reversals, the experiment ends and the threshold for that vector as the average of the chromaticities corresponding to the reversals was automatically calculated. The step size used in the staircase followed a dynamic rule (for more details on the CCT methodology see Regan et al. [14] and for CCT norms see Ventura et al. [21].

The thresholds along the protan, deutan, and tritan confusion lines (Fig. 3) were measured using the Trivector version, in which the three corresponding staircases were conducted

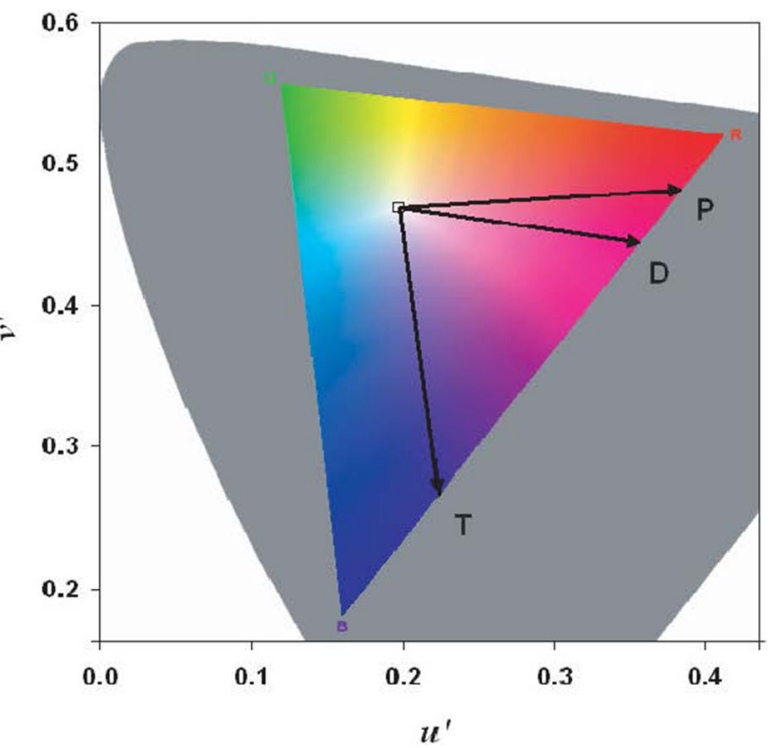

colors seen by the human visual system, and the color triangle exhibits the chromaticities that can be displayed on the video monitor at the luminance level used in the tests. The lines $P, D$, and $T$ correspond to the protan, deutan, and tritan, respectively, confusion lines tested in the Trivector protocol

simultaneously, interleaved, changing randomly from one to the other to avoid hysteresis. Periodically, a control target with strong saturation was presented and was used as catch trials. The threshold was computed for each staircase after six reversals had occurred expressed the average chromaticity defined by the last four reversals. The test lasted 3-5 min.

\section{Response Reliability}

The CCT software incorporates a reliability testing procedure with catch trials. Those catch trials were presented at random times during the test session and constitute about $10 \%$ of the stimuli. One color was used for the catch trial stimulus, defined in CIE 1976 coordinates: $u^{\prime}=0.119 ; \mathrm{v}^{\prime}=0.391 ;$ vector length $=1100 u^{\prime} v^{\prime}$ units. That saturated chromaticity can be discriminated by the background chromaticity even by patients with severe color vision impairment and congenital color blindness. This procedure tests for the ability of the subject to respond correctly to the target, which depends on the understanding of instructions 


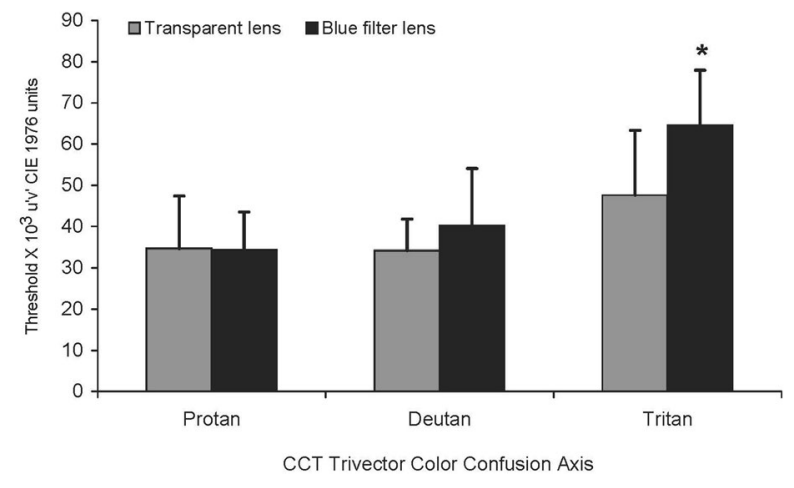

Fig. 3 CCT Trivector color discrimination thresholds for protan, deutan, and tritan color confusion axis performed under the blue filter and transparent lens conditions. For tritan axis there was a statistical difference between the conditions with higher thresholds for the blue filter lens condition

and on the attention directed to the task during the testing session. We define the percentage of correct responses to these catch trials as a measure of reliability as $100 \%$, i.e., all of the catch trials were correctly reported. The correct responses to catch trials means that the participant was performing the required task correctly during the entire testing session.

\section{Contrast Sensitivity}

Contrast sensitivity functions for luminance modulations were measured using the PSYCHO for Windows version 2.36 linked to a VSG 2/4 graphics board, allowing a 14-bit resolution (Cambridge Research Systems, Rochester, Kent, UK). Stimuli were presented on a $19^{\prime \prime}$ super-bright video monitor (Trinitron GFD-420; Sony, Tokyo, Japan) at a resolution of $1024 \times 768$ pixels (total of 786,432 active pixels), with a refresh rate of about $100 \mathrm{~Hz}$ non-interlaced scanning.

The stimuli were achromatic sinusoidal gratings presenting on a field of $4^{\circ} \times 4^{\circ}$ visual angle, at a constant average luminance of $34.4 \mathrm{~cd} \mathrm{~m}^{-2}$ at the following spatial frequencies: $3.0,6.0,12.0,18.0$ and 30.0 cycles per degree (cpd). Contrast sensitivities were obtained by varying the contrast with the psychophysical method of adjustments provided by the software PSYCHO. The sensitivity measurements were made for each spatial frequency using the
Method of Limits (MOL) and were calculated as the mean of three ascending and descending trials.

\section{Subjective Report}

Immediately after the end of the contrast sensitivity test, the participants were asked to answer the following question: "What filter gives you a more comfortable vision, the transparent or the yellow filter?".

\section{Statistical Analysis}

Statistical analysis was performed with the software Statistica (StatSoft v. 6, Inc., Tulsa, OK, USA). The full descriptive analysis was performed. Statistical differences among the groups were verified with the Student $t$ test for the dependent sample, since the same participant performed measurements on both lens conditions. Adhesion to the normal distribution was checked with the Kolmogorov-Smirnov test. Power test and Effect size were calculated for our sample size.

\section{RESULTS}

\section{Contrast Sensitivity}

Contrast sensitivity functions were measured in all 15 subjects. Data are shown in Table 1 and Fig. 4. The calculated statistical power was 0.81 and the critical $t$ value was 2.17. Paired Student $t$ test did not show statistical difference between the results obtained with the blue and the transparent filters.

Since chromatic aberrations have more impact at high spatial frequencies, we compared the contrast sensitivity measured with the transparent and blue filters at $30 \mathrm{cpd}$. We found that $8 / 15$ (61.5\%) subjects had higher contrast sensitivity with the transparent filter when compared with the results obtained with the blue filter $\left(X^{2}=0.18 ; p=0.632\right)$. Those reductions occurred for the highest spatial frequency.

However, the subjective impression of comfortable vision showed that $13 / 15$ (87\%) subjects referred a more comfortable vision under blue light filter lens condition. This bias toward the subjective preference for the blue filter lens 

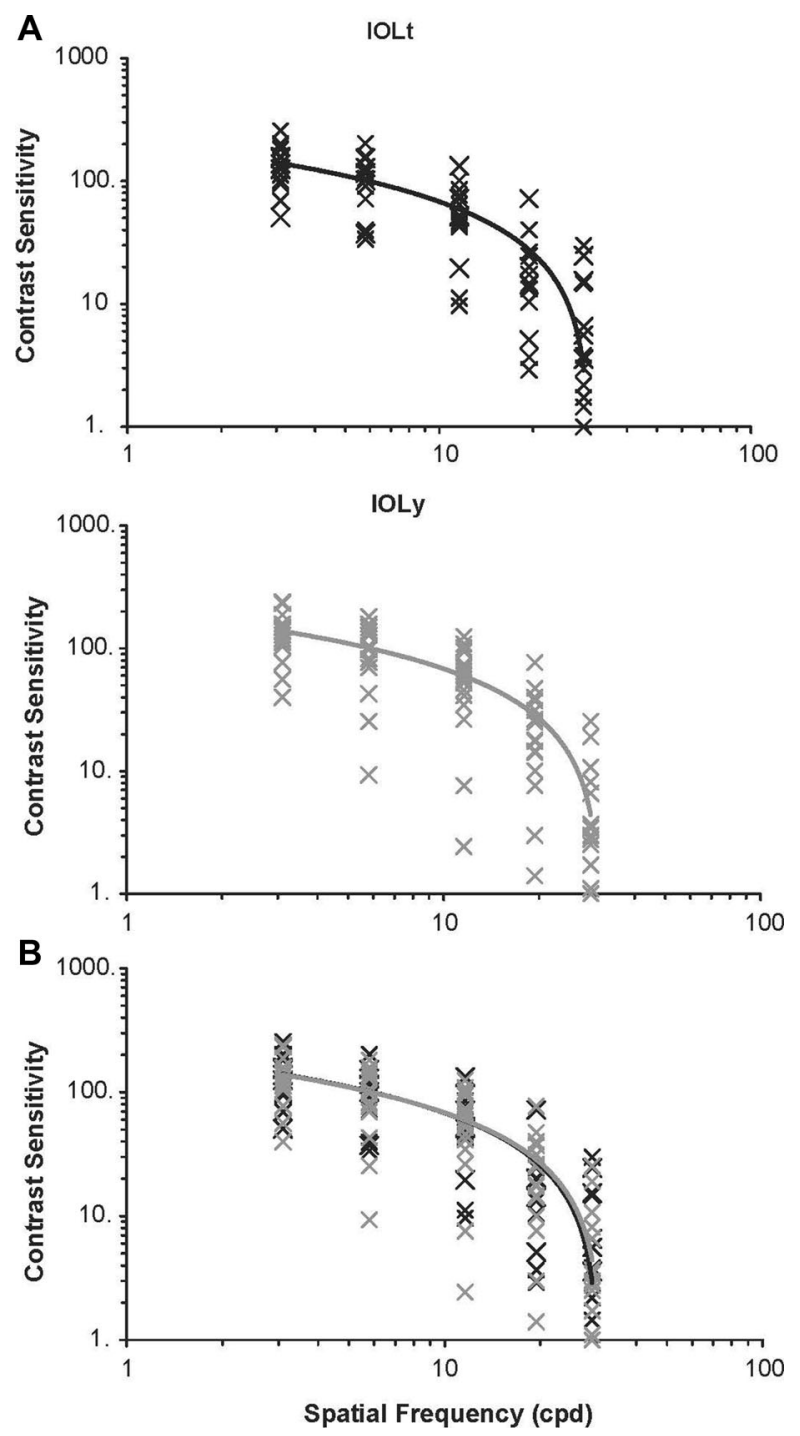

Fig. 4 Contrast sensitivity functions measured with blue light filter lens (a superior; in black) and with transparent lens ( $\mathbf{a}$ inferior; in gray). The $X$ letters are the individual thresholds and the solid line is the contrast sensitivity function adjusted to the points. The superimposition of both contrast sensitivity function (b) shows a highly similar function profiles and contrast thresholds for all spatial frequencies tested

has a statistical significance $\left(X^{2}=5.59\right.$; $p=0.016)$.

\section{Color Vision}

Color vision was measured in 13/15 (87\%) and their data are shown in Table 2. Statistical higher thresholds for the blue light filter were found in tritan confusion axis $(t=-3.60$; $p=0.003$, effect size $=0.86$; high effect). Thresholds measured in protan $(p=0.926)$ and deutan $(p=0.092)$ axes did not differ significantly (Fig. 5).

For the protan axis there was a mean increase (in $u^{\prime} v^{\prime}$ CIE 1976 units) for the thresholds of about $8 \%$ with the blue filter compared with the thresholds of the transparent filter. For the deutan and the tritan axes there was a mean increase in the thresholds of about 23 and $57 \%$, respectively, with the transparent filter compared with the thresholds of the blue filter.

The subjective impression showed that all the 13 subjects referred a worse color vision under blue light filter condition mainly for blues and purple hues.

\section{DISCUSSION}

The present study shows that the blue light filter intraocular lens impairs color vision for the blue-yellow (tritan) color confusion axis. Our results agree with Mester's [10] work which used the Farnsworth-Munsell 100-hue test to evaluate the effect of the blue filter lens on color vision and found a significant reduction in color discrimination for hues in the blue region. However, in contrast to the Mester [10] study, our patients reported more difficulty in detecting colors in the tritan axis, not just in the blue portion of the CIE color space.

Other studies reported no change in color vision in patients with the blue filter lens. Cionni et al. [6] and Landers et al. [5] using Farnsworth-Munsell 100 hue. This test has a moderate-to-low sensitivity in detecting subtle color vision defects. The absence of statistical difference between the patients with clear IOL and yellow IOL for color vision could be due to the low sensitivity test used in those studies.

The impairment in color vision for the tritan axis was expected in subjects wearing the blue light filter. The yellow pigment in the filter acts filtering the ultraviolet and short wavelengths [2]. Because of the differences in the spectral absorbance of the $\mathrm{S}$ and $\mathrm{M}$ photoreceptors in the region of the spectral absorbance of the 
Table 2 Color vision data obtained with IOLt and IOLy

\begin{tabular}{|c|c|c|c|c|c|c|c|c|}
\hline \multirow[t]{2}{*}{ ID } & \multirow[t]{2}{*}{ Age } & \multirow[t]{2}{*}{ Eye } & \multicolumn{3}{|c|}{ CCT Trivector IOLt ${ }^{a}$} & \multicolumn{3}{|c|}{ CCT Trivector IOLy } \\
\hline & & & Protan & Deutan & Tritan & Protan & Deutan & Tritan \\
\hline 3 & 23 & OD & $30^{c}$ & 29 & 59 & 23 & 33 & 67 \\
\hline 4 & 25 & OS & 44 & 36 & 36 & 30 & 48 & 66 \\
\hline 5 & 18 & OS & 23 & 34 & 23 & 39 & 36 & 32 \\
\hline 6 & 21 & OD & 23 & 44 & 55 & 39 & 42 & 58 \\
\hline 7 & 21 & OS & 28 & 34 & 68 & 21 & 31 & 76 \\
\hline 8 & 23 & OD & 26 & 33 & 26 & 26 & 44 & 82 \\
\hline 9 & 28 & OS & 40 & 54 & 42 & 52 & 71 & 70 \\
\hline 10 & 31 & OS & 38 & 33 & 39 & 33 & 26 & 60 \\
\hline 11 & 18 & OD & 33 & 29 & 54 & 26 & 39 & 70 \\
\hline 12 & 20 & OD & 41 & 29 & 31 & 33 & 26 & 60 \\
\hline 13 & 21 & OS & 70 & 26 & 70 & 39 & 64 & 78 \\
\hline 14 & 18 & OS & 26 & 28 & 54 & 47 & 30 & 72 \\
\hline 15 & 19 & OD & 29 & 36 & 62 & 38 & 33 & 48 \\
\hline Mean & 22.0 & & 35.1 & 34.2 & 47.6 & 34.3 & 40.2 & 64.5 \\
\hline SD & 4.0 & & 13.2 & 7.6 & 15.8 & 9.2 & 13.9 & 13.4 \\
\hline
\end{tabular}

${ }^{a}$ IOLt_transparent IOL

b IOLy-Blue light filter IOL

' Value in 'u'v' CIE 1976 units

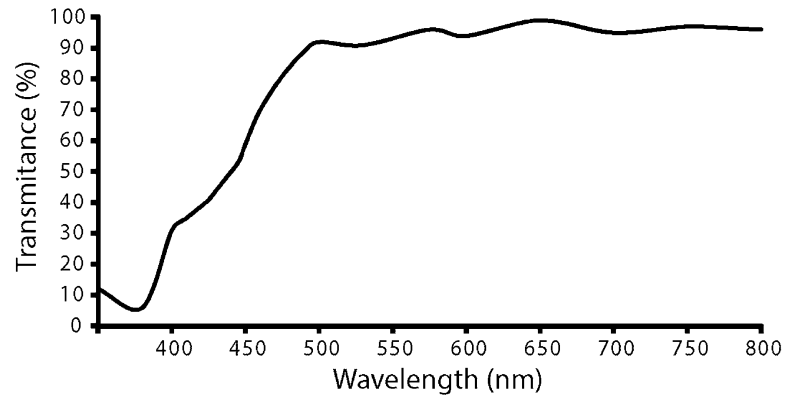

Fig. 5 Blue light spectrum filter spectral transmittance curve Adapted from Castro et al. [29]

filter, the effect of the filtering differed for each color confusion axis. We measured a mean increase of $57 \%$ in color discrimination threshold for the tritan axis under the blue filter lens condition compared with the transparent lens condition. For the deutan axis the increase in thresholds was about $23 \%$. For the protan axis, we found the opposite effect. In this color confusion axis, the lens filtering promoted an "advantage" in color discrimination and we measured an increase of about $8 \%$ under transparent lens compared to blue filter lens conditions. This result suggests that the yellow pigment of the blue filter has a strong filtering effect for the short wavelengths, a moderate filtering effect for the middle wavelengths and almost null filtering effect or even a discrete advantage for chromatic discriminations in the long wavelengths region of the light spectrum.

Chromatic input is mediated by three types of cones, which are connected to two distinct visual pathways-the parvocellular and the koniocellular pathways. The $\mathrm{L}$ and $\mathrm{M}$ cones are connected in opposition at the origin of the parvocellular pathway, which is related to 
red-green color vision, while the same cone types sum their inputs and oppose them to S-cone input to form the koniocellular pathway, which is related to blue-yellow vision [30]. Our results show an increase in thresholds for the short wavelengths compared to middle and long wavelengths, suggesting that the blue light filter is highly selective to the koniocellular pathway in comparison to the parvocellular pathway.

The confirmation of the present results that filtering short wavelengths influences color vision is important information for the ophthalmologist to take in consideration. Castro et al. [29] had found a decrease in SWAP MD when the filter was used compared with no filter. On this study, we had used the same filter, but in a different population also trying to simulate the effect of an intraocular lens with an ultraviolet filter. As the comparison of the effect before and after cataract surgery is not possible as the cataract itself works as a filter with no measurable spectrum, we think that testing lens in volunteers with no lens opacity would be a better methodology. Other studies had compared the effect of an intraocular lens with the ultraviolet filter when one eye was submitted to an IOL with filter and the other without filter [31].

Our results of luminance contrast sensitivity are in line with previous studies showing no difference in this visual function comparing blue light and transparent filters. However, the study of Pierre et al. [11] showed the opposite since they measured a reduction in the luminance contrast sensitivity in patients with blue filter lens.

Since chromatic aberrations are present in optical systems and affect the high spatial frequencies more than the low spatial frequencies [32], we decided to compare the results of contrast sensitivity measured at the high end of spatial frequencies, $30 \mathrm{cpd}$. The first interesting result was that about $61 \%$ of the patients had higher contrast sensitivity with the transparent lens. Second, the subjective impression of the visual comfort assessed by a question at the end of the contrast sensitivity test showed that $87 \%$ referred a more comfortable vision with the yellow lens. This result differs from other studies in which the subjects did not report perceived differences $[3,9]$.

We argue that this discrepancy can be explained based on the chromatic aberration filtering performed by the blue light filter. The similar results evidenced by the non-statistical difference in the contrast sensitivity measured at $30 \mathrm{cpd}$ could be explained by the fact that luminance contrast sensitivity is mediated by the $\mathrm{L}$ and $\mathrm{M}$ cones. Since the S-cones do not have a substantial contribution to the luminance contrast function [33], the short wavelength aberrations would not cause impairment in the measures that we performed. However, the filtering of those short wavelength aberrations could give a subjective impression of a clearer vision, which justified the preference to the blue light filter pointed out by $87 \%$ of the subject.

Despite the preference of the participants for the colored lens, it is important to note that this lens blocks wavelengths that are critical for ipRGCs cells [28]. There are no conclusive studies yet, however, reducing the incidence of short wavelengths in the retina may lead the patient to present symptoms related to insomnia, circadian rhythm change, mood changes among others not yet sufficiently evidenced.

\section{Future Directions}

The use of the Trivector protocol of the Cambridge colour test (CCT) for clinical studies could be considered a new level of color vision tests, in which meets a nice and reliable psychophysical protocol; colors and saturation levels are defined dynamically and precisely on the CIE chromaticity space; short time test need since it takes around $3 \mathrm{~min}$ to a complete threshold measurement on protan, deutan, and tritan color confusion axes, and it is easy to understand since responses were similar to Landolt C's visual acuity test. It had been used to study color vision impairment on retinal diseases like dominant optical atrophy (DOA) [15], glaucoma [16], multiple sclerosis patients [20], occupational mercury vapor intoxication [22], and on groups of 11,778 Leber Hereditary Optic Neuropathy patients [23]. Subclinical 
impairments were also measured in Duchenne Muscular Dystrophy patients [18], which evidenced its potential for high sensitivity clinical diagnosis. Also, CCT did not show binocular summation nor learning effect [17], which are evident on the other color vision tests $[6,10]$.

Future studies using color vision tests should be attentive to the color vision test chosen. The most frequent tests used for clinical studies are the FM100H and the Ishihara plates. The former is a test designed to measure performances on color order, thus it has low sensitivity to detect color deficiencies, since it uses middle-to-high saturated colors on intermediary luminance levels. The Ishihara plates were created to detect congenital color vision deficiencies, and then did not detect blue-yellow color deficiencies, which are the most frequent impairments on color discrimination in acquired diseases. A better color vision test would be Lanthony D15d used together with FM15H (D15) since both covers all the color range and two levels of saturation. However, the color separation between the caps is too large, decreasing the sensitivity of the test. The CCT uses a four alternative forced-choice protocol which reduces the patient's guessing rate increasing the reliability of the threshold measured, changes dynamically the chromaticity (hue plus saturation) on a complex color space and is faster and easier than any other clinical color vision test.

A relevant criticism regarding our study made by ourselves was the use of lens mounted on an ophthalmological support which is not the same situation of an implanted lens. The interaction with the aqueous and vitreous humor could generate some optical changes that could not be tested here. Also, other visual changes due to surgery procedures also could change the visual outcome compared with our results. We believe that the results of our study could be considered the desired result if we theoretically did not consider the changes in the lens and in the eye after the lens implant surgery. New studies conducted in patients with colored lens implants, which will address directly those questions are needed.

Future contributions will also include the color vision thresholds in patients with symptoms related to short wavelength filtering on
ipRGCs as sleep dysfunction, photophobias, impaired circadian rhythm, and mood instabilities. Some reports have been published on Parkinson's [34], Alzheimer's [35], DOA [36], and LHON [37], but the literature on that topic is scarce.

In conclusion, blue-yellow color vision is impaired with the blue light filter in this controlled situation, in which it was compared with the transparent filter. No quantitative differences were found in the luminance contrast sensitivity comparing the blue light and transparent filters. However, the blue light filter was reported to be more comfortable than the transparent filter. Visual comfort versus visual performance should be analyzed considering the needs of each patient for the better IOL prescriptions.

\section{ACKNOWLEDGEMENTS}

The research was supported by Grants from FAPESP Projeto Temático 02/12733-8, FINEP\#66.95.0407.00, CNPq\#523303/95-5. MFC, APJ and DFV are CNPq research fellows. All named authors meet the International Committee of Medical Journal Editors (ICMJE) criteria for authorship for this manuscript, take responsibility for the integrity of the work as a whole, and have given final approval for the version to be published.

Disclosures. Marcelo Fernandes da Costa, Augusto Paranhos Júnior, Claudio Luiz Lottenberg, Leonardo Cunha Castro and Dora Fix Ventura have nothing to disclose.

Compliance with Ethics Guidelines. All procedures were approved and they were in accordance with the ethical standards of the ethical committee on human experimentation and with the Declaration of Helsinki 1964, as revised in 2013. Informed consent was obtained from all participants for being included in the study.

Data Availability. The datasets during and/ or analyzed during the current study are 
available from the corresponding author on reasonable request.

Open Access. This article is distributed under the terms of the Creative Commons Attribution-NonCommercial 4.0 International License (http://creativecommons.org/licenses/ by-nc/4.0/), which permits any noncommercial use, distribution, and reproduction in any medium, provided you give appropriate credit to the original author(s) and the source, provide a link to the Creative Commons license, and indicate if changes were made.

\section{REFERENCES}

1. Eberhard R, Roberti P, Prunte C. Intraindividual comparison of color perception and contrast sensitivity with and without a blue light-filtering intraocular lens. Eur J Ophthalmol. 2009;19(2):235-9.

2. Schmidinger G, Menapace R, Pieh S. Intraindividual comparison of color contrast sensitivity in patients with clear and blue-light-filtering intraocular lenses. J Cataract Refract Surg. 2008;34(5):769-73.

3. Wirtitsch MG, Schmidinger G, Prskavec M, Rubey M, Skorpik F, Heinze G, Findl O, Karnik N. Influence of blue-light-filtering intraocular lenses on color perception and contrast acuity. Ophthalmology. 2009;116(1):39-45.

4. Muftuoglu O, Karel F, Duman R. Effect of a yellow intraocular lens on scotopic vision, glare disability, and blue color perception. J Cataract Refract Surg. 2007;33(4):658-66.

5. Landers J, Tan TH, Yuen J, Liu H. Comparison of visual function following implantation of Acrysof Natural intraocular lenses with conventional intraocular lenses. Clin Exp Ophthalmol. 2007;35(2):152-9.

6. Cionni RJ, Tsai JH. Color perception with AcrySof natural and AcrySof single-piece intraocular lenses under photopic and mesopic conditions. J Cataract Refract Surg. 2006;32(2):236-42.

7. Raj SM, Vasavada AR, Nanavaty MA. AcrySof Natural SN60AT versus AcrySof SA60AT intraocular lens in patients with color vision defects. J Cataract Refract Surg. 2005;31(12):2324-8.

8. Rodriguez-Galietero A, Montes-Mico R, Munoz G, Albarran-Diego C. Comparison of contrast sensitivity and color discrimination after clear and yellow intraocular lens implantation. J Cataract Refract Surg. 2005;31:1736-40.

9. Yuan Z, Reinach P, Yuan J. Contrast sensitivity and color vision with a yellow intraocular lens. Am J Ophthalmol. 2004;138(1):138-40.

10. Mester U, Holz F, Kohnen T, Lohmann C, Tetz M. Intraindividual comparison of a blue-light filter on visual function: AF-1 (UY) versus AF-1 (UV) intraocular lens. J Cataract Refract Surg. 2008;34(4):608-15.

11. Pierre A, Wittich W, Faubert J, Overbury O. Luminance contrast with clear and yellow-tinted intraocular lenses. J Cataract Refract Surg. 2007;33(7):1248-52.

12. Shah SA, Miller KM. Explantation of an AcrySof Natural intraocular lens because of a color vision disturbance. Am J Ophthalmol. 2005;140:941-2.

13. Mollon JD, Reffin JP. A computer-controlled colour vision test that combines the principles of Chibret and of Stilling. J Physiol Lond. 1989;414:5.

14. Regan BC, Freudenthaler N, Kolle R, Paulus W, Mollon JD. Colour discrimination thresholds in Parkinson's disease: results obtained with a rapid computer-controlled colour vision test. Vision Res. 1998;38:3427-31.

15. Simunovic MP, Votruba M, Regan BC, Mollon JD. Colour discrimination ellipses in patients with dominant optic atrophy. Vision Res. 1998;38:3413-9.

16. Castelo-Branco M, Faria P, Forjaz V, Kozak LR, Azevedo H. Simultaneous comparison of relative damage to chromatic pathways in ocular hypertension and glaucoma: correlation with clinical measures. Invest Ophthalmol Vis Sci. 2004;45:499-505.

17. Costa MF, Ventura DF, Perazzolo F, Murakoshi MT, Silveira LCL. Absence of binocular summation, eye dominance and learning effects in color discrimination. Vis Neurosci. 2006;23:461-9.

18. Costa MF, Oliveira AGF, Feitosa-Santana C, Zatz M, Ventura DF. Red-green color vision impairment in Duchenne muscular dystrophy. Am J Hum Genet. 2007;80:1064-75.

19. Goulart PRK, Bandeira ML, Tsubota D, Oiwa NO, Costa MF, Ventura DF. A computer-controlled color vision test for children based on the Cambridge Colour Test. Vis Neurosci. 2008;25:1-6.

20. Moura ALA, Teixeira RAA, Oiwa NN, Costa MF, Feitosa-Santana C, Callegaro D, Hamer RD, Ventura DF. Chromatic discrimination losses in multiple 
sclerosis patients with and without optic neuritis using the Cambridge Colour Test. Vis Neurosci. 2008;25:463-8.

21. Ventura DF, Silveira LC, Rodrigues AR, et al. Preliminary norms for the Cambridge Colour Test. In: Mollon JD, Pokorny J, Knoblauch K, editors. Colour and defective colour vision. 1st ed. New York: Oxford University; 2003. p. 331-9.

22. Ventura DF, Costa MTV, Costa MF, Berezovsky A, Salomão SR, Simões AL, Lago M, Pereira LHMC, Faria MAM, De Souza JM, Silveira LCL. Multifocal and full-field electroretinogram changes associated with color-vision loss in mercury vapor exposure. Vis Neurosci. 2004;21:421-9.

23. Ventura DF, Quiros $\mathrm{P}$, Carelli V, Salomão SR, Gualtieri M, Oliveira AGF, Costa MF, Berezovsky A, Federico S, De Negri AM, Sadum AA. Chromatic and luminance contrast sensitivities in asymptomatic carriers from a large Brazilian pedigree of 11778 Leber hereditary optic neuropathy. Invest Ophthalmol Vis Sci. 2005;46:4809-14.

24. Regan BC, Reffin JP, Mollon JD. Luminance noise and the rapid determination of discrimination ellipses in colour deficiency. Vision Res. 1994;34:1279-99.

25. Derrington AM, Krauskopf J, Lennie P. Chromatic mechanisms in lateral geniculate nucleus of macaque. J Physiol. 1984;357:241-65.

26. Lee BB, Valberg A, Tigwell DA, Tryti J. An account of responses of spectrally opponent neurons in macaque lateral geniculate nucleus to successive contrast. Proc R Soc Lond B. 1987;230:293-314.

27. Valberg A, Lee BB, Tryti J. Simulation of responses of spectrally opponent neurones in the macaque lateral geniculate nucleus to chromatic and achromatic light stimuli. Vision Res. 1987;27:867-82.

28. Sand A, Schmidt TM, Kofuji P. Diverse types of ganglion cell photoreceptors in the mammalian retina. Prog Retin Eye Res. 2012;31:287-302.
29. Castro LC, de Souza CE, Soriano ES, Melo LA Jr, Paranhos A Jr. Influence of blue light spectrum filter on short-wavelength and standard automated perimetries. Arq Bras Oftalmol. 2006;69(5):725-9.

30. Xu X, Ichida JM, Allison JD, Boyd JD, Bonds AB, Casagrande VA. A comparison of koniocellular, magnocellular and parvocellular receptive field properties in the lateral geniculate nucleus of the owl monkey (Aotus trivirgatus). J Physiol. 2001;531(1):203-18.

31. Kara-Junior N, Jardim JL, de Oliveira Leme E, Dall'Col M, Susanna R Jr. Effect of the AcrySof Natural intraocular lens on blue-yellow perimetry. J Cataract Refract Surg. 2006;32:1328-30.

32. Thibos LN, Bradley A, Still DL. Interferometric measurement of visual acuity and the effect of ocular chromatic aberration. Appl Opt. 1991;30(16):2079-87.

33. Dobkins KR, Gunther KL, Peterzell DH. What covariance mechanisms underlie green:red equiluminance, luminance contrast sensitivity and chromatic (green:red) contrast sensitivity? Vision Res. 2000;40:613-28.

34. Archibald NK, Clarke MP, Mosimann UP, Burn DJ. The retina in Parkinson's disease. Brain. 2009;132(5):1128-45.

35. Burns A, Allen H, Tomenson B, Duignan D, Byrne J. Bright light therapy for agitation in dementia: a randomized controlled trial. Int Psychogeriatr. 2009;21(4):711-21.

36. Zanna C, Ghelli A, Porcelli AM, Karbowski M, Youle RJ, Schimpf S, et al. OPA1 mutations associated with dominant optic atrophy impair oxidative phosphorylation and mitochondrial fusion. Brain. 2008;131(2):352-67.

37. Wakakura M, Yokoe J. Evidence for preserved direct pupillary light response in Leber's hereditary optic neuropathy. Br J Ophthalmol. 1995;79(5):442-6. 